\title{
PHYTOCHEMICAL SCREENING AND EVALUATION OF ANTI-INFLAMMATORY ACTIVITY OF AERIAL PART EXTRACTS OF PLANTAGO MAJOR L.
}

\author{
JYOTI VANDANA ${ }^{1 *}$, GUPTA A K ${ }^{2}$, ALOK MUKERJEE ${ }^{3}$
}

${ }^{1}$ Department of Chemistry, SHUATS, Allahabad, Uttar Pradesh, India. ${ }^{2}$ Department of Forensic Science, SHUATS, Allahabad, Uttar Pradesh, India. ${ }^{3}$ Department of Pharmacognosy, United Institute of Pharmacy, Allahabad, Uttar Pradesh, India. Email: jyoti.mani@shiats.edu.in

\author{
Received: 17 May 2017, Revised and Accepted: 02 June 2017
}

\section{ABSTRACT}

Objective: This study aims to perform phytochemical screening and investigate anti-inflammatory activity of extract from aerial part of the plant Plantago major L.

Methods: Preliminary phytochemical screening of plant extract was carried out using standard qualitative procedures and anti-inflammatory activity was evaluated using carrageenan-induced paw edema model in male Wistar albino rats using plethysmometer. Diclofenac sodium (10 mg/kg, b.w.) was used as standard drug.

Results: Preliminary phytochemical screening of the different extracts revealed that they were rich in secondary metabolite compounds such as carbohydrates, tannins, steroids, flavonoids, terpenoids, glycosides, fats and oils, alkaloids, phenolic compounds, and iridoid glycosides. The antiinflammatory activity was evaluated using carrageenan-induced paw edema models in Wistar albino rats. The anti-inflammatory activity of methanolic extract (ME) was found to be dose dependent in carrageenan-induced paw edema model. The ME has shown significant (p<0.05) inhibition of paw edema, $61.11 \%$ and $55.55 \%$ on $4^{\text {th }} \mathrm{hr}$ at the doses of 900 and $600 \mathrm{mg} / \mathrm{kg}$, respectively.

Conclusion: The results of the present study demonstrate that ME of the aerial parts of the plant possess significant (p<0.05) anti-inflammatory potential.

Keywords: Phytochemical screening, Plantago major L., Anti-inflammatory activity, Carrageenan, Diclofenac sodium.

(C) 2017 The Authors. Published by Innovare Academic Sciences Pvt Ltd. This is an open access article under the CC BY license (http://creativecommons. org/licenses/by/4. 0/) DOI: http://dx.doi.org/10.22159/ajpcr.2017.v10i9.20031

\section{INTRODUCTION}

In recent times, phytochemical and pharmacological investigations have acquired great information and knowledge for the use of medicinal plants by revealing the presence of active principles and actions on humans and animals. There is necessity to increase the efforts in screening and collecting plants for the development of new, environmentally friendly, and safe medicinal agents [1]. Inflammation is an important physiological reaction, which occurs in response to injury of cells and body tissues through different factors such as infections, chemicals, thermal and mechanical injuries by limiting damage, and promoting tissue repair [2]. When inflammatory process takes place, it protects our body from diseases by releasing cells and mediators that combat foreign substances and prevent infection. It is noted that excessive inflammation leads to rheumatoid arthritis, psoriasis, and other inflammatory diseases [3]. The five basic symptoms of inflammation are redness, swelling, heat, pain, and deranged function known since the ancient time. Inflammation is categorized as acute and chronic, where acute inflammation is the initial stage of inflammation that persists for short time, whereas when the inflammation is for longer period, it is termed as chronic inflammation. Depending on the intensity of inflammation, mediators generated in the affected area can reach the circulation and cause fever. Inflammation is a complex pathophysiological process, mediated by a variety of signaling molecules. These molecules produced by leukocytes, macrophages, and mast cell are responsible for the generation of inflammatory mediators such as nitric oxide, prostaglandin (PG) E2, and tumor necrosis factor- $\alpha$ that bring about edema formation as a result of extravasation of fluid and proteins and accumulation of leukocytes at the inflammatory site [4]. The drugs used in the treatment of inflammation are nonsteroidal anti-inflammatory drugs (NSAIDs) and SAIDs. These drugs have toxic effects such as ulceration and bleeding, renal damage, hypertension, hyperglycemia, etc [5]. Therefore, continuous research is done to reduce such side effects. Whereas medicinal plants are known as alternate and important natural source of chemical substances with potential therapeutic effects as pain relievers and anti-inflammatory agents with less side effects.

Plantaginaceae is one of the most diverse family of plants [6]. The genus Plantago L. comprises 265 species with a worldwide distribution [7]. In Asia and Europe, Plantago species have been used in folk medicine for the treatment of various diseases such as wound healing, problems relating to digestive tracts, and asthma as a diuretic and antiinflammatory drug $[8,9]$. Plantago major belongs to the genus Plantago, family Plantaginaceae and is commonly known as plantain. It is an old medicinal plant known for centuries [10]. It was discovered about 4000 years ago in Europe, but are also found in some parts of Northern and Central Asia and has widely distributed worldwide, particularly in temperate, but also tropical parts. It is a small perennial plant with height about $15 \mathrm{~cm}$, but the size varies depending on the growth habitats [11]. In general, people call it as medicinal weed [12]. It is well-known traditional herbal plant to treat various diseases including skin diseases, infectious diseases, reduce pain and fever, reproduction, cancer, respiratory and digestive organs related problems [8]. In addition to the traditional uses of $P$. major, some researchers also prove its medicinal properties such as immune modulating property [13], antileukemia, antiviral, anticarcinogenic [14,15], antioxidant [16], anti-inflammatory, and analgesic activities [17]. These medicinal properties of $P$. major due to the presence of biologically active chemical compounds such as polysaccharides, lipids, caffeic acid derivatives, flavonoids, iridoid glycosides, terpenoids, alkaloids, and some organic acids $[8,12,18]$. Some studies reported that the leaves of $P$. major are used for its wound healing property, anti-inflammatory, antioxidant 
activity, immunoenhancing property [8-13], and its seeds are used to treat various gastrointestinal disorders. The aim of the present study is to investigate the claimed folkloric information of plantain used for wound healing and other inflammatory problems using carrageenaninduced paw edema model for anti-inflammatory activity.

\section{MATERIALS AND METHODS}

\section{Collection and identification of plant material}

Aerial parts of $P$. major were collected from Forest Research Institute (FRI), Dehradun. It was identified and authenticated by Dr. (Mrs.) Veena Chandra, Head, Botany Division, FRI, Dehradun, Uttarakhand, India. A voucher specimen has been preserved in laboratory for the future reference with accession number 164439A/B/C.

\section{Preparation of plant material}

The collected plant material was washed thoroughly in water, air dried at room temperature under shade for 2 weeks, and pulverized in laboratory electric grinder. The powdered plant material was kept in air tight containers for further use.

\section{Preparation of plant extracts}

The shade-dried, powdered plant material was weighed and then successively extracted with solvents of increasing polarity starting with benzene, chloroform, ethanol, methanol by soxhlet extraction method, and separately, whole water extract was prepared. The obtained extracts were filtered separately and each extract was concentrated by distilling off the solvent and then evaporating it to dry by placing it on a porcelain dishes on electric water bath. The percentage yield of extracts was calculated and kept in air tight containers for pharmacognostic and pharmacological studies.

\section{Animals}

Male albino rats of Wistar strain weighing 150-200 g were procured from the Industrial Toxicology Research Centre, Mahatma Gandhi Marg, Lucknow, Uttar Pradesh, India. The animals were kept for acclimatization under laboratory conditions for 1 week before the start of the study. Animals were housed 6 rats per polyacrylic cage with paddy husk as bedding at temperature of $25^{\circ} \mathrm{C} \pm 4^{\circ} \mathrm{C}$ and relative humidity of $50 \%-60 \%$ and light/dark cycle of $12 \mathrm{hrs} /$ day $[19,20]$ were used throughout the period of anti-inflammatory activity study. The animal in a group was recognized by mark of picric acid on the fur of each animal. Animals had free access to pellet feed and water ad-libitum. The experimental protocol was approved by the Institutional Animal Ethics Committee, United Institute of Pharmacy, Allahabad, India, as per the provisions made by CPCSEA, Government of India (Regd. No. 1451/P0/a/11/ CPCSEA). Animals were fasted overnight before and during experiment.

\section{Methods}

\section{Preliminary phytochemical screening}

The preliminary phytochemical screening of $P$. major aerial part extracts was carried out qualitatively for the presence of steroids, tannins, flavonoids, saponins, alkaloids, carbohydrates, glycosides, fats and oils, phenols, and iridoid glycosides. The preliminary phytochemcial screening for bioactive compounds was carried out by the standard methods [21-23]. The phytochemical examinations were performed on the liquid and dried extracts.

\section{Evaluation of anti-inflammatory activity of P. major}

The methanolic extract (ME) is the most potent extract selected for anti-inflammatory activity. The dose of ME was selected for anti-inflammatory activity on the basis of previously published literature [24-26]. The maximum tolerated dose (MTD) of P. major ME was found $2 \mathrm{~g} / \mathrm{kg}$ [27]; therefore, the LD50 is greater than $2 \mathrm{~g} / \mathrm{kg}$. The one-tenth of the MTD of the extract was selected for evaluation of anti-inflammatory activity [28]. Therefore, 300, 600, and $900 \mathrm{mg} / \mathrm{kg}$ doses of $P$. major extract were selected. The anti-inflammatory activity of the extract was done against carrageenan-induced rat paw edema model [29].

\section{Experimental design}

The animals were divided into five groups consisting of 6 rats in each group. Each group received a particular treatment such as control, positive control, and three different doses of ME. Before any treatment, each rat was weighed properly and the doses of the test samples, positive control, and control were calculated accordingly. Either of control vehicle, standard drug (diclofenac sodium), or methanolic crude extract was given orally. Acute inflammation was provided by injection of $0.1 \mathrm{ml}$ of $1 \%$ carrageenan into the subplantar surface of rat hind paw. Group I: served as control, rats received $1 \mathrm{ml}$ normal saline and $0.1 \mathrm{ml}$ of carrageenan. Group II: (Positive control) rats received diclofenac sodium (10 mg/kg b.w.p.o.) [30] and $0.1 \mathrm{ml}$ of carrageenan, Group III: (Test group), rat received ME of P. major (300 mg/kg b.w. p.o.) and $0.1 \mathrm{ml}$ of carrageenan. Group IV: (Test group), rat received $\mathrm{ME}$ of $P$. major (600 mg/kg b.w. p.o.) and $0.1 \mathrm{ml}$ of carrageenan. Group V: (Test group), rats received ME of P. major (900 mg/kg b.w.p.o.) and $0.1 \mathrm{ml}$ of carrageenan. The paw volumes were measured plethysmometrically [31] up to a fixed mark by displacement at $1,2,3$, and $4 \mathrm{hrs}$, after the administration of the standard and test drugs. The percentage inhibition of inflammation was calculated as inhibition of edema volume [32] as follows:

Percentage inhibition of inflammation $=\frac{\left(1-V_{t}\right)}{V_{c}} \times 100$

Where $V_{t}$ is the average paw edema volume of extract of treated group or positive control group.

$\mathrm{V}_{\mathrm{c}}$ is the paw volume of the control that received only vehicle.

\section{Statistical analysis}

The data obtained from the experimental work are expressed as mean \pm standard deviation. The statistical analysis of the antiinflammatory activity of plantain was analyzed using one-way analysis of variance followed by Dunnett's $t$-test. Differences between the mean of treated animals and control group were considered statistically significant at $\mathrm{p}<0.05$ for $t$-test.

\section{RESULTS AND DISCUSSION}

\section{Preliminary phytochemical screening}

Phytochemicals are plant chemicals known to play an important role in biological activity of medicinal plants. There is an increasing interest in phytochemicals present in P. major due to their potential use in food supplements and pharmaceuticals. It has different phytochemicals in its leaves, seeds, stem, and roots, which really have restorative properties and can likewise be utilized as taxonomic markers [8]. The preliminary phytochemical screening was done to identify the secondary metabolites present in the different solvent extracts.

The results of qualitative phytochemical screening as given in the Table 1 shows the presence of phytochemicals such as carbohydrates, reducing sugar, alkaloids, flavonoids, tannins, steroids, terpenoids, glycosides, fats and oils, phenols, and iridoid glycosides whereas saponins and anthraquinones were absent in all the extracts. The result shows that carbohydrates, flavonoids, phenols, and iridoid glycosides were present in high amount as compared to other phytochemicals investigated. The maximum phytochemicals were present in ME as compared to other extracts. The polarity of extraction solvent may influence the number of bioactive compounds obtained from the plant extract. It was reported that methanol was found more desirable to extract the phytoconstituents. It was studies that methanol was $20 \%$ more effective than ethanol and $73 \%$ more effective than water [33]. The phytochemicals identified gave an idea about the chemicals present in this plant which may be responsible for the pharmacological activities and the reason for their use as a traditional medicine worldwide. The phytochemical evaluation of various phytoconstituents were graded as very high $(+++)$, moderate $(++)$, low $(+)$, and nil $(-)$ based on the intensity of the colored reaction product. The extraction yield calculated for all extracts showed that methanol extract recorded higher percentage of yield. All these five extracts gave different chemical 
Table 1: Preliminary phytochemical screening of different solvent extracts of aerial part of Plantago major

\begin{tabular}{|c|c|c|c|c|c|c|}
\hline S.No. & Name of test & Benzene extract & Chloroform extract & Ethanol extract & Methanol extract & Water extract \\
\hline \multirow[t]{4}{*}{1} & Carbohydrates & & & & & \\
\hline & Molisch's test & + & + & ++ & ++ & - \\
\hline & Barfoed's test & - & + & + & ++ & - \\
\hline & Fehling's test & - & + & + & +++ & + \\
\hline \multirow[t]{3}{*}{2} & Tannins & & & & & \\
\hline & Ferric chloride test & - & - & + & ++ & - \\
\hline & Lead acetate test & - & - & + & + & - \\
\hline 3 & Liebermann-Burchard test & + & + & + & + & - \\
\hline \multirow[t]{2}{*}{4} & Anthraquinones & & & & & \\
\hline & Borntrager's test & - & - & - & - & - \\
\hline \multirow[t]{2}{*}{5} & Saponins & & & & & \\
\hline & Foam test & - & - & - & - & - \\
\hline \multirow[t]{3}{*}{6} & Flavonoids & & & & & \\
\hline & Ferric chloride test & - & - & + & +++ & + \\
\hline & Sodium hydroxide test & - & - & + & ++ & - \\
\hline 7 & Salkowski test & + & - & + & ++ & - \\
\hline \multirow[t]{3}{*}{8} & Alkaloids & & & & & \\
\hline & Dragendroff's test & - & - & + & + & - \\
\hline & Mayer's test & - & - & + & + & - \\
\hline \multirow[t]{4}{*}{9} & Glycosides & & & & & \\
\hline & Keller-killiani's test & - & + & + & ++ & - \\
\hline & Salkowski test & - & - & + & + & + \\
\hline & Borntrager's test & - & - & - & - & - \\
\hline \multirow[t]{3}{*}{10} & Phenols & & & & & \\
\hline & Ferric-chloride test & - & - & ++ & +++ & + \\
\hline & Lead acetate test & - & - & + & + & - \\
\hline \multirow[t]{2}{*}{11} & Fats and oils & & & & & \\
\hline & Stain test & + & + & - & - & - \\
\hline \multirow[t]{2}{*}{12} & Iridoid glycosides & & & & & \\
\hline & Trim and Hill's test & - & - & + & +++ & - \\
\hline
\end{tabular}

-: Nil, +: Low, ++: Moderate, +++: Very high

composition due to different polarity of the extraction solvent. It may be due to high polarity of methanol solvent which can describe high variety of plant constituents than the other solvents.

\section{In vivo anti-inflammatory activity}

Different solvent extracts of $P$. major were evaluated for the presence of phytochemicals before the anti-inflammatory study. The result in Table 1 shows that among all the extracts, ME gave positive tests for most of the phytoconstituents during phytochemical screening. The extract was also selected because of its high extractive value. Therefore, the ME is the most potent extract selected for anti-inflammatory activity. Carrageenan-induced paw edema as an in vivo model of inflammation has been used to assess the anti-inflammatory activity of the test extract. The effect of extract on carrageenan-induced edema at different hours of study was compared to that of control for the evaluation of anti-inflammatory activity on the basis of percent inhibition of paw edema volume.

Carrageenan induced inflammation model is a useful acute experimental model for the estimation of anti-inflammatory effect. The development of edema in the paw of the rat after the injection of carrageenan is due to the release of histamine, serotonin, and Prostaglandin (PG) [34]. Carrageenan is phlogistic agent which induced edema develops by mediators in two phases, so inflammation produced by carrageenan has a biphasic effect. The first phase is due to release of mediators such as histamine and serotonin occurs within 0-2 hrs [35] and the second accelerating phase edema is attributed to bradykinins and PG release $\left(>4^{\text {th }} \mathrm{hr}\right.$ ) [36]. The results of the present study showed that methanol extract of $P$. major significantly inhibited the formation of the rat paw edema in the early and late phases. Most of the anti-inflammatory medicines are effective in the last phase of edema formation [37]. As shown in Table 2, standard drug diclofenac sodium showed significant inhibition of edema at $4^{\text {th }} \mathrm{hr}(81.48 \%)$. Our results of anti-inflammatory activity as given in Table 2 confirmed that the ME significantly reduced both phases of the carrageenan-induced edema. The significant anti-inflammatory activity has shown by methanol extract at higher concentration (at dose of $900 \mathrm{mg} / \mathrm{kg}$ body weight) which was comparable to standard. In this study, ME showed dose-dependent activity in both the phases of inflammation. The P. major inhibited the edema during acute phase of inflammation is possibly by inhibiting the mediators of inflammation.

The anti-inflammatory activity of $P$. major extract may be due to the presence of phytoconstituents given in Table 1 . Some researchers reported that $P$. major contains biologically active chemical compounds such as polysaccharides, lipids, caffeic acid derivatives, flavonoids, iridoids glycosides, and terpenoids. Alkaloids and some organic acids have also been identified in this plant [8-18]. This study also observed that highest anti-inflammatory activity was found in the ME at a dose of $900 \mathrm{mg} / \mathrm{kg}$. This result was similar to the findings of Beara et al. [18] and Hussan et al. [38]. It is reported that anti-inflammatory activity of P. major is contributed by flavonoids such as baicalein and hispidulin and iridoid glycosides such as aucubin [8]. Guillen et al. [17] studied an aqueous extract of $P$. major leaves at a dose of $1 \mathrm{~g} / \mathrm{kg}$ for antiinflammatory activity. The study concluded that aqueous extract of P. major has anti-inflammatory and analgesic activities. In the other study, the ME of $P$. major seeds was investigated for anti-inflammatory activity. The findings of the study suggested that $P$. major seeds' extract has anti-inflammatory activity [39]. Reina et al. [10] study the in vitro effects of $P$. major extract, baicalein and aucubin, on human neutrophil respiratory burst activity. They concluded that $P$. major extract, baicalein and aucubin, significantly inhibited the production of reactive oxygen species from the neutrophils. Numerous studies have reported that anti-inflammatory and analgesic activities of medicinal plants have been related the presence of tannins, flavonoids, alkaloids, phenolic compounds $[40,41]$, and iridoid glycosides $[42,43]$. Therefore, the antiinflammatory activity observed in $P$. major may be due to the activity or activities of one compound or a combination of a number of compounds 
Table 2: Effect of ME of aerial part of Plantago major on carrageenan-induced paw edema in rats

\begin{tabular}{|c|c|c|c|c|c|c|}
\hline \multirow[t]{2}{*}{ Group } & \multirow[t]{2}{*}{ Treatment } & \multirow[t]{2}{*}{ Dose (mg/kg b.w.p.o.) } & \multicolumn{4}{|c|}{ Increase in paw volume (ml) } \\
\hline & & & $1 \mathrm{hr}$ & 2 hrs & 3 hrs & 4 hrs \\
\hline I & Control & $1 \mathrm{ml} \mathrm{NS}$ & $0.33 \pm 0.017$ & $0.42 \pm 0.015$ & $0.51 \pm 0.023$ & $0.54 \pm 0.023$ \\
\hline III & $\mathrm{ME}$ & 300 & $0.23 \pm 0.020 *(30.30)$ & $0.24 \pm 0.028 *(42.85)$ & $0.26 \pm 0.01 *(49.01)$ & $0.27 \pm 0.02 *(50.00)$ \\
\hline IV & ME & 600 & $0.21 \pm 0.020 *(36.36)$ & $0.22 \pm 0.030 *(47.61)$ & $0.23 \pm 0.011 *(54.90)$ & $0.24 \pm 0.015 *(55.55)$ \\
\hline V & ME & 900 & $0.19 \pm 0.005^{*}(42.42)$ & $0.20 \pm 0.01 *(52.38)$ & $0.21 \pm 0.005 *(58.82)$ & $0.21 \pm 0.026 *(61.11)$ \\
\hline
\end{tabular}

All the results are expressed as mean \pm SD of six animals in each group; number in parenthesis indicates percentage inhibition in increase in paw volume. ${ }^{*} \mathrm{p}<0.05$ when compared with control, statistically significant. ME: Methanolic extract, SD: Standard deviation, NS: Normal saline

belongs to the different classes of compounds present in aerial parts of P. major [44]. Further studies are in process for the isolation of active constituents responsible for anti-inflammatory activity and its possible mechanism.

\section{CONCLUSION}

The present study has shown that the P. major is a rich source of phytochemicals. The ME of the aerial part of plantain possessed a significant anti-inflammatory effect on paw edema induced by carrageenan. The carrageenan-induced inflammation model is a significant model for anti-inflammatory agents acting by the mediators of acute inflammation. The present study concluded that $P$. major is a rich source of phytoconstituents and effective in acute inflammatory disorders and is suggested for continual use as herbal anti-inflammatory medicine.

\section{ACKNOWLEDGMENT}

We are grateful to the Vice-Chancellor, SHUATS, Allahabad, Uttar Pradesh, India, for providing necessary facilities and Mr. Sunil Kumar Singh from United Institute of Pharmacy, Naini, Allahabad, India, for helping in physical evaluation of the method.

\section{REFERENCES}

1. Simon MK, Nafarnda WD, Obeta SS. Iridoids glycosides isolated from Combretum molle stem bark aqueous methanol extract. Glob Vet 2012;8(3):237-43

2. Nathan C. Points of control in inflammation. Nature 2002;420(6917):846-52.

3. Franklin PX, Pillai AD, Rathod PD, Yerande S, Nivsarkar M, Padh H, et al. 2-amino-5-thiazolyl motif: A novel scaffold for designing antiinflammatory agents of diverse structures. Eur J Med Chem 2008;43(1):129-34.

4. White M. Mediators of inflammation and the inflammatory process. J Allergy Clin Immunol 1999;103:S378-81.

5. Divyasree MS, Bhagyasri Y, Lavakumar V, Kumar CK. An overview on anti-inflammatory activity of Indian herbal plants. Int J Res Pharm Nano Sci 2015;4(1):1-9.

6. Albach DC, Meudt HM, Oxelman B. Piecing together the new Plantaginaceae. Am J Bot 2005;92(2):297-315.

7. Taskova R, Evstatieva L, Handjieva N, Popov S. Iridoid patterns of genus Plantago L. And their systematic significance. J Nat Res 2002;57(1-2):42-50.

8. Samuelsen AB. The traditional uses, chemical constituents and biological activities of Plantago major L. A review. J Ethnopharmacol 2000;71(1-2):1-21

9. Velazquez MM, Lanza AM, Matellano LF. Polyphenolic compounds from Plantago lagopus. J Nat Res 2000;55(11-12):877-80.

10. Reina E, Al-Shibani N, Allam E, Gregson KS, Kowolik M, Windsor LJ. The effects of Plantago major on the activation of the Neutrophil Respiratory Burst. J Tradit Complement Med 2013;3(4):268-72.

11. Tarvainen M, Suomela J, Kallio H, Yang B. Triterpene acids in Plantago major: Identification, quantification and comparison of different extraction methods. Chromatographia 2010;71(3):279-84.

12. Jamilah J, Sharifa AA, Sharifah NR. GC-MS analysis of various extracts from leaf of Plantago major used as traditional medicine. World Appl Sci J 2012;17:67-70

13. Gomez-Flores R, Calderon CL, Scheibel LW, Tamez-Guerra P, Rodriguez-Padilla C, Tamez-Guerra $\mathrm{R}$, et al. Immunoenhancing properties of Plantago major leaf extract. Phytother Res 2000;14(8):617-22.

14. Chiang LC, Chiang W, Chang MY, Ng LT, Lin CC. Antiviral activity of Plantago major extracts and related compounds in vitro. Antiviral Res 2002;55(1):53-62.

15. Chiang LC, Chiang W, Chang MY, Lin CC. In vitro cytotoxic, antiviral and immunomodulatory effects of Plantago major and Plantago asiatica. Am J Chin Med 2003;31(2):225.

16. Pourmorad F, Hosseinimehr SJ, Shahabimajd N. Antioxidant activity, phenol and flavonoid contents of some selected Iranian medicinal plants. Afr J Biotechnol 2006;5(11):1142-5

17. Guillen ME, Emim JA, Souccar C, Lapa AJ. Analgesic and antiinflammatory activities of the aqueous extract of Plantago major L. Int J Pharm 1998;35(2):99-104.

18. Beara IN, Lesjak MM, Jovin ED, Balog KJ, Anackov GT, Orcic DZ, et al. Plantain (Plantago L.) Species as novel sources of flavonoid antioxidants. J Agric Food Chem 2009;57(19):9268-73.

19. Burger GT, Miller CL. Animal care and facilities. In: Hayes AW, editor. Principle and Methods of Toxicology. $2^{\text {nd }}$ ed. NY: Raven Press Ltd.; 1989. p. 527-31.

20. Goyal RK. Practical in Pharmacology. $3^{\text {rd }}$ ed. Ahmedabad: Shah Prakashan Publishers; 2002.

21. Harborne JB. Phytochemical Methods: A Guide to Modern Techniques of Plant Analysis. $3^{\text {rd }}$ ed. London: Chapman and Hall; 1998. p. 120.

22. Sofowora A. Medicinal Plants and Traditional Medicine in Africa. Vol. 2. New York: John Wily and Sons; 1993. p. 6-56.

23. Trease GE, Evans WC. Pharamacognosy. Vol. 14. London: W. B. Scandars Company Ltd.; 1989. p. 269-300.

24. Atta AH, Abo EL-Sooud K. The antinociceptive effect of some Egyptian medicinal plant extracts. J Ethnopharmacol 2004;95(2-3):235-8

25. Atta AH, Nasr SM, Mouneir SM. Potential protective effect of some plant extracts against carbon tetrachloride-induced hepatotoxicity. Afr J Tradit Complement Altern Med 2006;3(3):1-9.

26. Ozaslan M, Karagoz ID, Kilic IH, Cengiz B, Kalender ME, Guldur ME, et al. Effect of Plantago major sap on Ehrlich ascites tumours in mice. Afr J Biotechnol 2009;8(6):955-9.

27. Barua CC, Pal SK, Roy JD, Buragohain B, Talukdar A, Barua AG, et al. Studies on the anti-inflammatory properties of Plantago erosa leaf extract in rodents. J Ethnopharmacol 2011;134(1):62-6.

28. Handa SS, Sharma A. Hepatoprotective activity of and rographolide from Andrographis paniculata against carbon tetrachloride. Indian J Med Res 1990;92:276-83.

29. Winter CA, Risley EA, Nuss GW. Carrageenin-induced edema in hind paw of the rat as an assay for anti-iflammatory drugs. Proc Soc Exp Biol Med 1962;111:544-7

30. Suralkar AA, Rodge NK, Kamble RD, Maske KS. Evaluation of antiinflammatory and analgesic activities of Tamarindus indica seeds. Int J Pharm Sci Drug Res 2012;4(3):213-7.

31. Harris JM, Spencer PS. A modified plethysmographic apparatus for recording volume changes in the rat paw. J Pharm Pharmacol 1962;14:464-6.

32. Süleyman H, Demirezer LO, Kuruüzüm A, Banoglu ZN, Göçer F, Ozbakir G, et al. Antiinflammatory effect of the aqueous extract from Rumex patientia L. Roots. J Ethnopharmacol 1999;65(2):141-8.

33. Metivier RP, Francis FJ, Clydesdale FM. Solvent extraction of anthocyanins from wine pomace. J Food Sci 2006;45(4):1099-100.

34. Sonia RK, Irchhaiyaa R, Dixit V, Bhat ZA, Wani HA, Najar AH. Antiinflammatory activity of Kirganelia reticulata (Poir). Baill. Root by carrageenan-induced rat paw oedema model. Int J Pharm Pharm Sci 2014;6(1):520-3

35. Rahman MD, Sharmin RR, Nazimuddin MM, Zaman MU, Rana S, Ahmed N. Antinociceptive and anti-inflammatory effect of Crinum 
asiaticum bulb extract. Asian J Pharm Clin Res 2011;4(3):34-7.

36. Suba V, Murugesan T, Kumaravelrajan R, Mandal SC, Saha BP. Antiinflammatory, analgesic and anti peroxidative efficacy of Barleria lupulina Lindl extract. Phytother Res 2005;19(8):695-9.

37. Niemegeers CJ, Verbruggen FJ, Janssen PA. Effect of various drugs on carrageenan induced oedema in the rats hind paw. J Pharmacol 1964;16:810-6.

38. Hussan F, Mansor AS, Hassan SN, Tengku Nor Effendy Kamaruddin TN, Budin SB, Othman F. Anti-inflammatory property of Plantago major leaf extract reduces the inflammatory reaction in experimental acetaminophen-induced liver injury. Evid Based Complement Alternat Med 2015;2015:347861.

39. Türel I, Ozbek H, Erten R, Oner AC, Cengiz N, Yilmaz O. Hepatoprotective and anti-inflammatory activities of Plantago major $\mathrm{L}$.
Indian J Pharmacol 2009;41(10):120-4

40. Wang JR, Zhou H, Jiang ZH, Wong YF, Liu L. In vivo anti-inflammatory and analgesic activities of a purified saponin fraction derived from the root of Ilex pubescens. Biol Pharm Bull 2008;31(4):643-50.

41. Garcia-Leme J, Nakamura L, Leite MP, Silva MR. Pharmacological analysis of the acute inflammation process induced in rats paw by local injection of carrageenan and heating, Br J Pharmacol 1973;64:91-8.

42. Viljoen A, Mncwangi N, Vermaak I. Anti-inflammatory iridous of botanical origin. Curr Med Chem 2012;19(14):2104-27.

43. Shim KM, Choi SH, Jeong MJ, Kang SS. Effects of aucubin on the healing of oral wounds. In Vivo 2007;21(6):1037-41.

44. Yam MF, Ang LF, Ameer OZ, Salman IM, Aziz HA, Asmawi MZ. Anti-inflammatory and analgesic effects of Elephantopus tomentosus ethanolic extract. J Acupunct Meridian Stud 2009;2(4):280-7. 